\section{Coats of many colours}

\section{Anne McLaren}

The Coat Colors of Mice. By W.K. Silvers. Pp.379. (Springer: Berlin, Heidelberg and New York, 1979.) DM59.60, \$32.80.

SOME targets of scientific study are inherently attractive. One such is soap bubbles. Another is coat colours and patterns. In the days when I knew R.A. Fisher, the father of modern statistics, his true pride and love was for mouse genetics, and to be asked the effect of umbrous on an agouti pink-eyed brown background would really make his eyes twinkle.

W.K. Silvers' book is also a labour of love. There is no mention of Sturtevant's intriguing suggestion that Mendel discovered his 'laws' of segregation and assortment by illicitly crossing differentcoloured mice in his monastery cell, later using his curiously exact pea ratios as a mere didactic demonstration; but in other respects the early history of the subject is well covered. The references include more than 20 papers published in the first two decades of this century on the genetics of coat colour in mice, starting with the classic 1902 paper of Cuénot. One of these pioneers is still living, Naomi Mitchison, who, with her brother J.B.S. Haldane, published in 1915 the linkage between albino and pink-eyed dilution, the first to be established in any mammal. A start was also made in those early years on the chemistry of mouse pigmentation (Onslow, 1915) and on the developmental analysis of lethal yellow (Ibsen and Steigleder, 1917), while C.C. Little's lifelong interest in mouse spotting genes gave rise to a series of papers beginning in 1913 .

Moving to more modern times, Silvers pays tribute to Grüneberg's monumental Genetics of the Mouse (Nijhoff: The Hague, 2nd edition; 1952), to Searle's Comparative Genetics of Coat Colour in Mammals (Logos Press: London; 1968), to Mintz's illuminating studies on experimental chimeras ('allophenic' mice) and to the great amount of assistance that he received from Rita Phillips, whose very recent death is a sad loss to mouse genetics as well as to her many friends and colleagues.

Apart from its aesthetic appeal, the study of coat colours embraces not only genetics (148 alleles at 63 loci), but also biochemistry, cytology, histology, anatomy, embryology and endocrinology. Silvers does justice to all these aspects. The first half of the book, in which he deals with the various colour-controlling loci and their complex interactions, is perhaps more satisfactory than the second half, which covers spotting genes, chimeras and $\mathrm{X}$-chromosome mosaics. The etiology of spotting and coat colour pattern is still widely debated, and even the experimental evidence is sometimes conflicting. Silvers does his best to summarize the literature, but the picture that emerges is patchy in more senses than one. For example, in the field with which I am most familiar, he perpetuates confusion by failing to make clear that Mintz's 'standard' or archetypal pattern is a valuable abstraction rather than an observed pattern ("observed relatively rarely" is misleading when the true probability, for one side of the mouse alone, is $2^{-16}$, less than 1 in 100,000); he does not mention Lyon's interesting suggestion that the frequent brindled sectors of chimeras arise because each territory may be colonized, not by one but by two 'primordial melanoblasts', of the same or contrasting genotype; and he affords the same status to the clonal theory of pattern formation for hair follicle chimeras as for melanocyte chimeras, though the evidence is far less cogent for the former than for the latter.

But these are minor grumbles. The book as a whole will be a standard reference work in every mouse genetics laboratory for many years to come. Not only does it make admirably clear the complex interplay of genetic (and in some cases environ-

\section{The classic electricians}

\section{W.D. Hackmann}

Electricity in the 17th and 18th Centuries. By J. L. Heilbron. Pp. 606. (University of California Press: Berkeley, Los Angeles and London, 1979.) $£ 24$.

AN ambitious work that deserves to become a classic in this subject. Not only has Professor Heilbron incorporated all the historical papers on early electricity that have appeared since I. B. Cohen's Franklin and Newton An Inquiry into Speculative Newtonian Experimental Science and Franklin's Work in Electricity as an Example Thereof (The American Philosophical Society: Philadelphia, 1956), but he has also included much new material, such as the importance of the seventeenth century Jesuit polymaths in the study of physics in general, and in electricity in particular. For those of us reasonably well versed in this subject, the main developments as given in this book are known, but it is useful to have such a broad and up-to-date survey. The general reader interested in the history of physics, or of electricity, should find this a fascinating story, although he might miss some of the finer philosophical or technical nuances. Any historical treatment of a scientific subject must contain inevitable mental) factors in determining coat colour, but it also uncovers areas where further research is badly needed. These include spotting genes, of course; the intriguing behaviour of silver, resembling the effects on pigmentation of irradiation, and perhaps also ageing; the 'reds' of the mouse fancy, and no doubt other fancy types also, not yet analysed genetically; and, above all, the need for a codification of colour, a decent set of colour standards, which although doubtless imperfect could hardly but improve on such phrases as "a dull brown colour", "a medium shade of sepia", "a faint cream or ivory color", "a brownish shade, a little lighter than an ordinary pink-eyed brown with a slight dull yellowish cast". The three colour plates in the present volume are not of very high quality, though better than nothing; really good colour reproduction would have presumably escalated the price unacceptably.

As it is, the book at about $£ 15$ is reasonably priced, there are good author and subject indexes, and the bibliography is comprehensive.

Anne McLaren is Director of the MRC Mammalian Development Unit, London. UK.

distortions as all is focused on specific aspects of the total picture, but by attempting such a broad canvas, Heilbron has managed to keep these distortions to a minimum.

A work of this nature, covering such a large time span, is inevitably faced with historiographical problems. Terms and concepts change their meaning, brought about by new discoveries and by changes in philosophical outlook, and this makes interpretation difficult. The author has to make it clear to the reader that a problem dealt with in the seventeenth century was handled differently from the same problem looked at by physicists one hundred years later. When surveying a subject over a very long period, it is possible to give it a false appearance of continuity, while the subject progressed (or changed) in a much more convoluted manner. In the context of this book, both the concepts of physics and of electricity changed dramatically during these two hundred years. The word 'electricity' was to undergo subtle changes in meaning during the century after its use by Sir Thomas Browne in his Pseudodoxia Epidemica: or, Enquiries into very many received tenents and commonly presumed truths (1646), causing endless confusion to historians of science in the past. At first it simply referred to the attractive property of amber and other substances. The word only began to denote a separate entity or substance causing the electrical behaviour of attraction and repulsion during the early 1740 s. Heilbron has coped admirably with this kind of problem, not least by the way 